\title{
Problems of Competitive Strategy Choice According to Industry and Regional Factors
}

\author{
Bogdanova Tatiana ${ }^{1 *}$, Karlik Mikhail ${ }^{2}$ \\ ${ }^{1}$ Peter the Great Saint-Petersburg Polytechnic University (SPbPU), Institute of Industrial Management, \\ Economics and Trade, Graduate School of Industrial Economics, 195251, 29, Polytechnicheskaya str., Saint- \\ Petersburg, Russia \\ 2International Management Institute of Saint-Petersburg (IMISP), Department of accounting and finance, \\ 199004, 50, $9^{\text {th }}$ line of Vasilievsky island, Saint-Petersburg, Russia
}

\begin{abstract}
An essential condition for sustainable development and maintenance of long-term competitiveness of a company lies in the formulation of an adequate and appropriate strategy. Strategic decisions should be based on a correct understanding of the results of systematic analysis carried out by managers to form sustainable competitive advantages. The following aspects are contemplated: industry and regional conditions within the strategic areas of activity and interests of the organization, prevailing forms and types of strategic interactions, level of innovative potential of the industry and region, and specific influencing factors of macro and micro levels. However, not only the socio-economic significance (efficiency and rationality) of the decision itself is really important but also the speed, and even more precisely the timeliness of its implementation, predetermined by the dynamics of industry factors. This paper examines the relationship of innovative strategies recommended to companies with the stage of the industry life cycle, along with the specifics of territorial and regional factors. It is argued that the use of classical competition tools or the use of innovative ones, including radical strategic approaches depend on the specifics of industry and regional factors. As an example, the logic and directions of innovative solutions for an energy company are considered.
\end{abstract}

Keywords: Business model; Competitive advantages; Radical competitive strategy; Strategic areas of activity; Territorial-regional factor

\section{Introduction}

The result of the process of developing, adopting, and implementing strategic actions both at the corporate and individual business levels depends on many interrelated aspects of enterprise management (Porter, 2005; Mednikov et al., 2018). Within the framework of the modern sustainable development concept, it is recognized that the competitiveness of an organization depends upon the management's ability to competently and timely respond to changes in socio-economic, environmental, and political factors that are changing both at the level of an individual territory and on a global scale (Nikolova et al., 2017a; Gutman et al., 2018). Globalization and integration of resource and product market processes increase risks and accelerate the dynamics of the external environmental influence, which pushes companies to constantly and rapidly search for new innovative areas for the application of resources and knowledge (Dvas and Dubolazova, 2018). 
In the existing modern conditions, it is important to analyze the development of an enterprise from the point-of-view of innovative activity as a modern form of competition. By focusing on innovation, companies have the opportunity to gain support from the government and consumers, which in turn will increase their competitiveness in the future. In the context of high dynamics of sectoral factors and ongoing social and technological transformations in society, it becomes relevant to identify the factors and principles of enterprise innovation policy formation (Shabunina et al., 2017; Berawi, 2020). The purpose of this study was to form a logic of approaches for justifying the choice of a company's strategic decision regarding tools of competition through innovation, with allowance for the influence of industry and territorial factors.

\section{Methods}

The material of this paper is presented via the usage of a comparative and systematic analysis of studies devoted to the formation of sustainable competitive advantages issues. The methodological basis of the research carried out in this paper is the methods of collecting and processing information, expert procedures, and a morphological approach, as well as the use of a number of theories and models. The significance of which has been proven by empirical experience, creating the methodological basis of the research carried out in this paper. Among these methodologies, the theory of industry consolidation by A.T. Kearney (Deans and Zeisel, 2004), models of the McKinsey corporate center (Foot et al., 2003), and models of competitive strategies "Strategic clocks" (D’Aveni, 1995; Faulkner and Bowman, 1995) which is a development of Porter's ideas regarding the classification of competitive strategies, are considered.

Business development presumes a certain logic (Figure 1) (Ragin, 2007) in creating the 'value' of the company to the investor and quantifying the growth of profitability within the core industry and market capitalization. The life cycle of an organization is based on an alternation of strategic actions of intensive and extensive growth, the success of which depends on the choice of adequate tools for a competitive strategy.

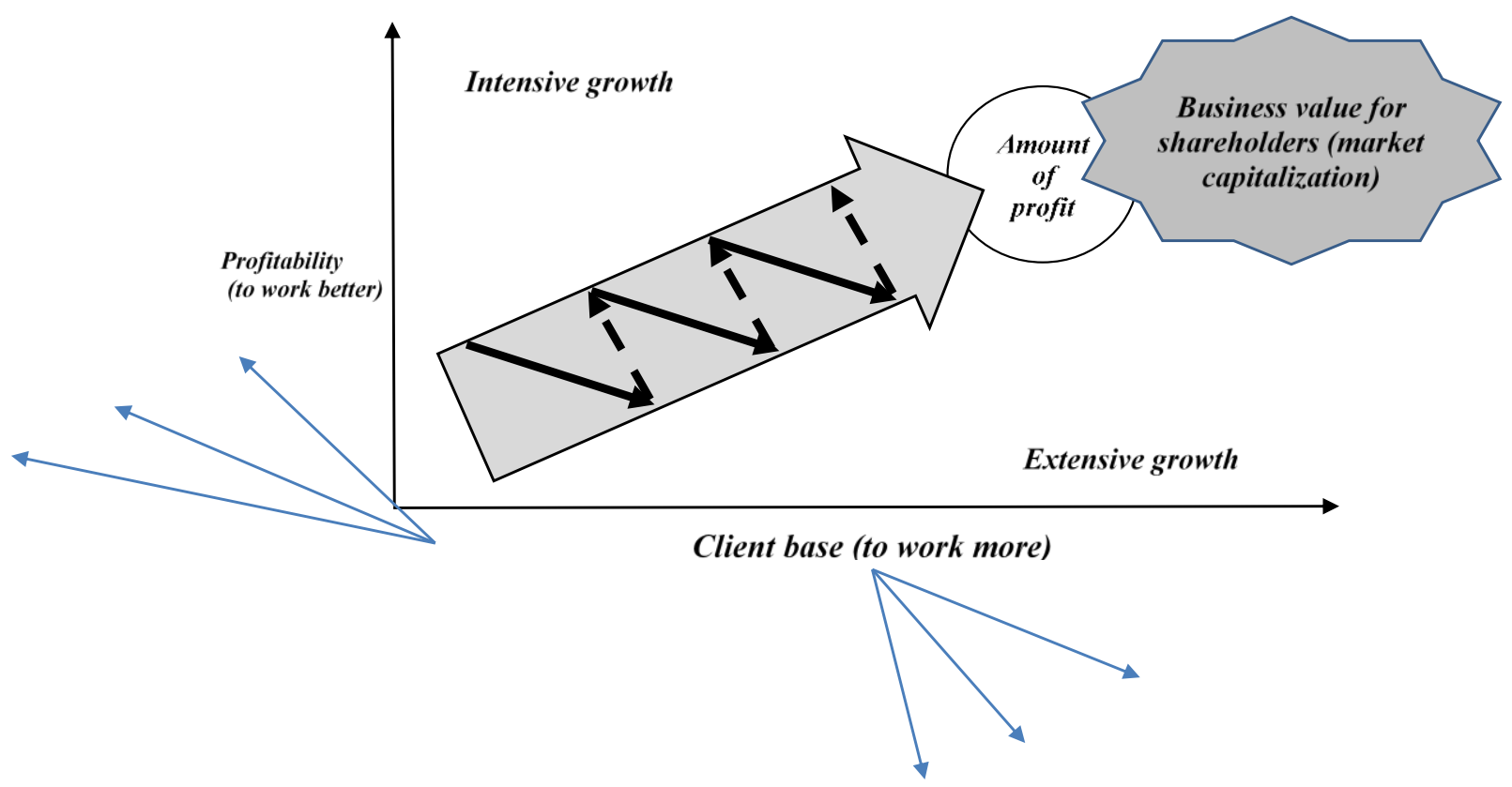

Figure 1 Business growth logic: financial business goal setting and ways to grow 
This study's main idea was to justify the decision to choose the type of competitive strategy based on the presence of: (a) the logic of effective organization management (a combination of strategic decisions of intensive and extensive growth); (b) classification of types of competitive strategies according to their impact on the companies' competence and consumer behavior; (c) the existence of stages in the industry development life cycle (industry structure, intensity of competition, speed of consolidation); and (d) availability of effective strategic solutions depending on the level of industry consolidation, competitive company's position, and specific industry and regional factors.

\section{Results and Discussion}

\subsection{Business Growth Logic}

Extensive growth presupposes the expansion of the company's activities through the implementation of various types of corporate-level strategies: territorial expansion, vertical and horizontal integration, and diversification. The successful implementation of such strategies leads to an increase in the customer base. Integration and diversification strategies are accompanied by an increase in various types of activities, including unrelated, which leads to an increase in costs, primarily implicit ones, associated with the discrepancy between the organizational and economic structure of the business and its external format.

Accordingly, the problem of managing continuous growth arises when the internal system of business organization (management system) does not keep pace with external growth. The profitability of operations and value of the company's capital gradually decrease due to increasing inefficiency. The decline in profitability to a certain critical level is a signal of the need to improve internal processes in accordance with the new business format. For example, to improve the company's performance, it is necessary to implement intensive growth strategies aimed at business process optimization and the increase in business unit's competitiveness. One of the elements of such reengineering is the introduction of new norms and standards for the company's activities along with automated information systems for managing business processes and implementation of various kinds of innovations, both at the product level and in all related business processes.

Consequently, an increase in the efficiency of resource usage for some time will be accompanied by a certain loss of sales volume, firstly, associated with the loss of non-target segments. Secondly, in most cases, the introduction of norms and standards of a new business format cannot fully consider the needs of all market segments in which the company operated prior to the implementation of an intensive growth strategy. Some of the cheapest and most expensive customers will be lost. The former will simply cease to be of interest for the company since they will not fit into the rate of return (they will have to go to competitors and their profitability may well grow in the future). The latter will not always be satisfied with the service standards, which the company will not stray from for the sake of best customer satisfaction.

Further development will require the next stage of extensive growth and its alternation with the intensive one. Consistent implementation of these strategic decisions ensures long-term profit growth and increased business value. The business growth logic shown in Figure 1 is obvious and understandable at first glance. In business practice, three extremely important points are often missed.

- Management systems, legal-organizational forms, the logic of organizing the main and auxiliary business processes, and even the managers at the head of the company must change in accordance with the chosen model of (intensive or extensive) growth. Unfortunately, universal management models do not exist for any organization. 
- Changing the organization's management system is a strategic decision in itself, which means a long-term, expensive and risky decision. In addition, such decisions must always be made in advance and with careful justification.

- Increased competition, globalization, and acceleration of the organization's external environment makes the need for reversals from extensive to intensive growth and viceversa more and more private, and the cost of an error and, most importantly, the untimeliness of such a reversal, more and more expensive.

These points led us to the idea that the strategy of any modern company that is claiming to grow, must in advance assume this zigzag movement, where the factors that predetermine the next reversal will be primarily environmental factors, under which the logic of business management must be rebuilt.

\subsection{Radical Competitive Strategy as an Industry Factor}

Competitive strategy presupposes step-by-step and gradual innovations that do not have a significant (and rapid) impact on customer behavior and the established business models of competing companies (cost leadership, differentiation, focusing, best value) (Porter, 2005). An innovative competitive strategy is based either on the destruction of existing business models, including those that appeared as a result of modern information management technologies introduction or on a significant change in consumer behavior via offering fundamentally new products, methods of purchasing, or after-sale service. A radical competitive strategy involves capitalizing on a radical innovation that disrupted the industry's previous business model and changed consumer's behavior. A radical competitive strategy always leads to the creation of a new environment, market, and industry (Markides and Geroski, 2006).

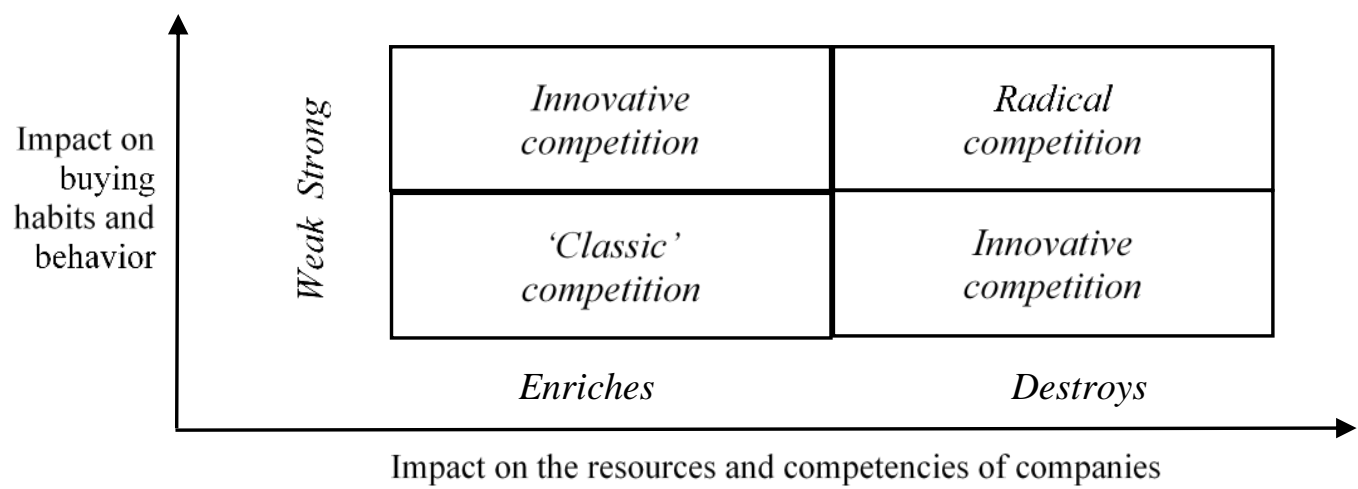

Figure 2 Classification of competitive strategies

This strategy can provide sustainable competitive advantages, monopoly super-profits, and rapid growth of the company. The advantage in this case is based on the fact that someone is the first in a given business, given territory, or new market. Along with it, new markets may appear as a result of new technology creation, the use of existing technologies in a new context, emergence of new personal needs, environmental problems, new financial instruments, and risk management tools (Abushova et al., 2018). The high risk of this strategy in comparison with classical strategies is always associated with high uncertainty, both of the development itself and the market reaction to a novelty. Therefore, enterprises undertake special measures to reduce commercial risk, including the creation of various forms of inter-firm cooperation (Bondarenko, 2016). 


\subsection{Priority Factors for the Competitive Strategy Type Choice}

Combining A.T. Kearney's industry consolidation model (Deans and Zeisel, 2004) with concepts of diversification, McKinsey's ideas on the role of the corporate center (Foot et al., 2003), and the model of competitive strategies "strategic clocks" (Ragin, 2007), makes it possible to develop a corporate asset management system, with allowance for the stage of development of each business unit in the industry and the current competitive position in the strategic group (Figure 3). The most successful will be those who can move up the consolidation curve the fastest. By capturing critical positions ahead of others, they will be able to secure industry leadership by correctly and timely implementing strategic decisions at the level of the business line.

The choice of a competitive strategy is determined, on the one hand, by sectoral factors, and on the other, by the position that a particular firm occupies within the industry and the strategic group. Changes in the nature of the competitive struggle leads to changes in the structure of the industry or the emergence of new foundations for competitive advantage.

Enterprises must respond not only to changes in the structure of the industry but also to adapt to changing conditions within their strategic group considering their competitive positions in it. At each enterprise, the classification of competitive advantages has its own characteristics and covers the required volume of various economic and managerial aspects. Because of the ongoing processes, digitalization automates the search and study of competitive advantages (Sokolitsyn et al., 2017; Balashova and Gromova, 2018; Setyaningrum et al., 2020).

Any enterprise has its own characteristics and specifics; therefore, the choice of a strategy to ensure the competitive advantages of its products for each of them is individual and depends not only on the stage of industry development and position of the company in it but directly on the goals of the company and capabilities for their achievements. According to the 'strategic hours' model, organizations achieve a competitive advantage by providing their customers with a product of higher quality or by maintaining lower costs relative to the average industry. The criterion of competitive advantage in this model is the combination of the 'perceived value by the consumer' and the 'price' of the product created by the company. This model helps to identify the main competitive strategies, as well as their possible change over time.

The strategic clock model combines well with the concept of industry consolidation determining the appropriate timing and use of one or another 'classic' competitive strategy (Figure 3). The figure presents a visualization of the industry development stages and changes in the company's possible competitive strategy at each stage. 


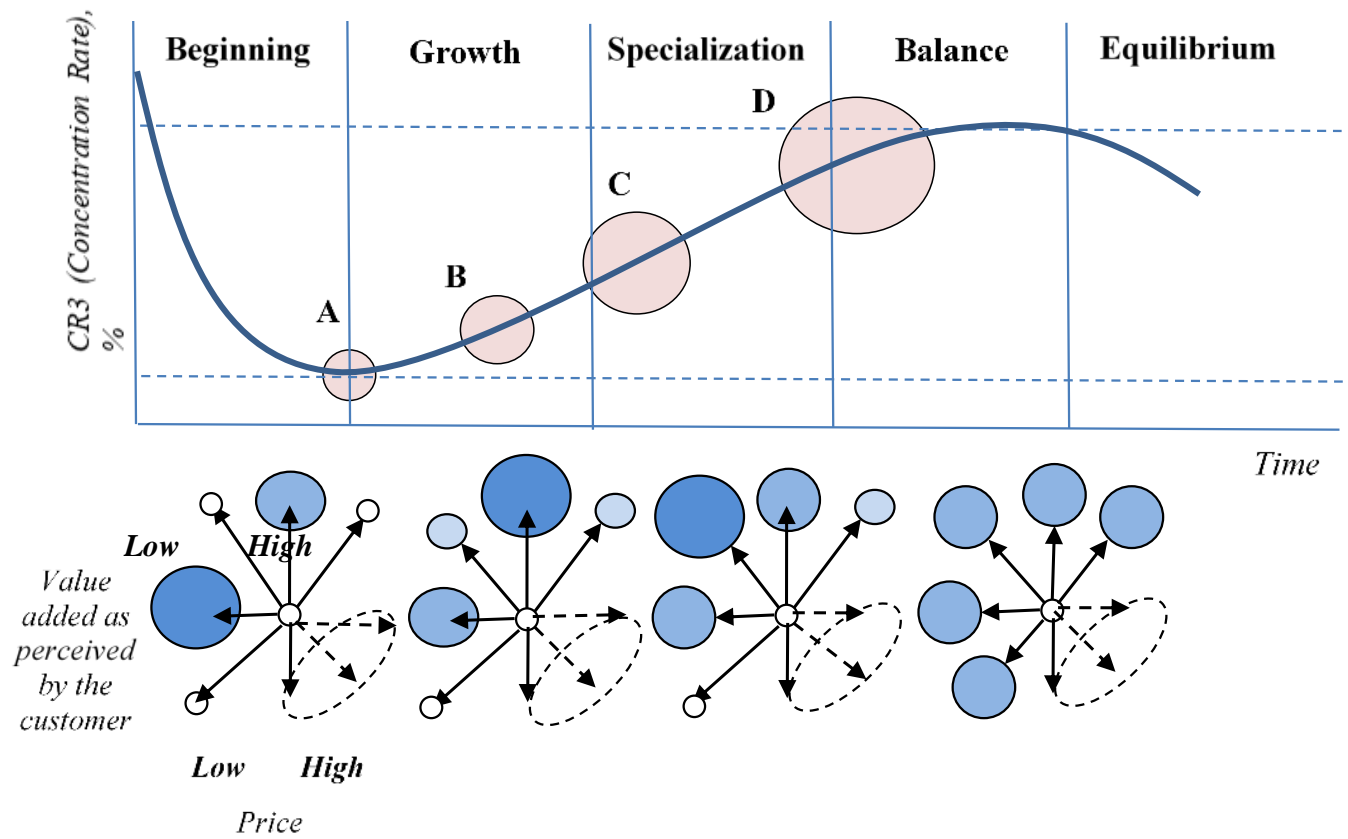

Figure 3 Effectiveness of basic and innovative competitive strategies at various stages of industry consolidation

Therefore, for example, at the first stage of the industry life cycle, the stage of innovations, opportunities, and risk, when industry standards have not yet been defined, the number of participants grows; provision of the company's growth is possible through the implementation of the territorial expansion strategy (Ragin, 2007). The most effective competitive approach at this stage will be the implementation of a low-price strategy combined with an industry average level of quality. In general terms, the level of product quality in the industry is determined by a specific market situation. Considering the existence of the life cycle of both the product and the industry, the very concept of quality as a combination of perceived consumer value and the price of the product changes over time (Zhogova et al., 2017). The task is reduced to not only ensure the relationship between production and the market, adapting supply to changing demand, but also targeting the impact on demand to create competitive advantages in each of the considered market segments.

Accordingly, those who, before others, identify and propose the best set of parameters of perceived consumer value and offer it at the average industry price will achieve success at the first stage. From this stage on, companies must focus on a differentiation strategy. On the one hand, this will increase the growth of the client base, and on the other hand, form the so-called industry standard, which consumers will strive for and competitors will have to follow. That will allow them to take leading positions in the second stage.

At the third stage, specialization, when it comes to toughening the competition between a decreasing number of players in a market that slows down the growth rate, about the relative saturation of the consumer market, the most effective approach would be to maintain a high level of quality at a lower price than the industry price level. Consideration must be given to the fact that if a company has reached the third stage, then it is a rather powerful player, and accordingly, its product or service is used by a wide audience of consumers, represented by various segments. Therefore, as can be seen from the figure 3, in addition to the hybrid strategy, the company, depending on the segment, can simultaneously implement both the 'low price' and 'differentiation' strategy to retain positions. However, the approach to the fourth stage speaks about the final saturation of 
the market and the relative obsolescence of the product. Competitive strategies in the core industry shift from differentiation to price leadership.

According to the studies carried out by Fomina and Alekseev (2018), on the basis of the Kearney model, 4 zones (A, B, C, D) can be distinguished, in relation to which policy options for innovative development can be formulated. Zone A corresponds to the border of the stages 'start - growth' of consolidation. A fundamentally new product has already appeared in the industry, a radical innovation, which is beginning to be actively applied in the production of companies in the industry. This stage is characterized by the formation of a technology platform and trial marketing. Significant investments in technological innovations are required to form competitive advantages by creating a national technological standard in the global market.

Zone B corresponds to the growth stage. It is necessary to invest in the sales of innovative products at this stage. However, if the industry has not created its own technology standard yet (foreign is accepted), then investment focuses on marketing of the final product. At the same time, investments in research \& development (R\&D) at this stage is ineffective due to the high competitive barriers created by global leaders.

Zone C: During the specialization phase, innovation increasingly focuses on meeting consumer needs for high quality products. Most small and medium-sized enterprises have limited resources and are involved in only one stage of the value chain (Caiazza and Stanton, 2016). Therefore, to gain a competitive advantage, companies are forced to cooperate with private and public organizations for the joint implementation of projects that lie beyond their boundaries. Partnerships with other firms create the possibility for the information exchange, facilitating effective inter-firm interaction to increase the innovative activity of its participants.

Zone D covers companies entering the balance stage. It is characterized by the presence of highly concentrated global markets in which technological breakthroughs are difficult within the framework of the existing technological platform. At this stage, it is economically expedient to invest in the production of a fundamentally new generation of the product. Unfortunately, the national management of the industries located in this zone do not have such an understanding, which is manifested in the localization of foreign technologies and industries of the previous generation. As practice shows, large companies start integrating in completely new directions. Over time, promising companies separate from their parent companies and form new industries. As a result, the cycle repeats. At the same time, organizational survival directly depends on the creation of new ideas and innovation cycles.

Thus, the allocation of four types of innovation policy, determined by the current level of industry concentration, makes it possible to differentiate the policies of their innovative development.

\subsection{Justification of Business Innovation Activity Considering Systematization of External Factors}

While planning innovative activities, companies must decide how much they want or are ready to change the existing business model and whether the goal of the strategy is to obtain a product with fundamentally new properties (Ivanov et al., 2012). The conditions influencing the choice are determined by specific factors that can be quantitatively and qualitatively assessed in terms of their impact (stimulating or limiting) on innovative activity aimed at creating new products and solutions.

Due to the high level of the national economy regions differentiation, the effectiveness of the company's innovation strategy depends not only on industry parameters, but also on the specifics of territorial and regional aspects, including the level of socio-economic development of the region, resource potential, regional innovation policy, and 
infrastructure, among others (Suryanegara, 2016; Aleksandr et al., 2017; Nikolova et al., $2017 \mathrm{~b}$ ). As a result of the factors study, a pattern was drawn up for making a decision on the formation of the competitive strategy (Figure 4), which is a morphological structure (image) of the most significant parameters complex that determines the conditions for innovative activities of organizations situated in the Russian Federation, and then the choice of an innovative strategy.

In Figure 4, the first two factors describe the industry specifics, the next five - primarily, regional features, and the last two - the specifics of the company as such. Note that the infrastructure in the figure means a rather broad and, most importantly, situational concept - the adaptability of the external (in this case, regional) environment for the successful growth of the industry and a specific organization - the availability of resources and the favorableness of external factors, for example, local legislation, development of transport infrastructure, availability of free labor resources, and availability of electric power, among others. For clarity, an example of a set of factors of the external and internal environment of an organization is highlighted in bold, which in turn predetermines the choice of the competitive strategy type.

So, for example, strategic innovative solutions of an energy company will change depending on the territory where this company is located, since in different regions, there will be different demand (population density, income level), degrees of self-sufficiency in raw materials and labor resources, regulation of carbon dioxide emissions, distribution, transmission, market structure, and electricity sales scheme (Deloitte, 2015).

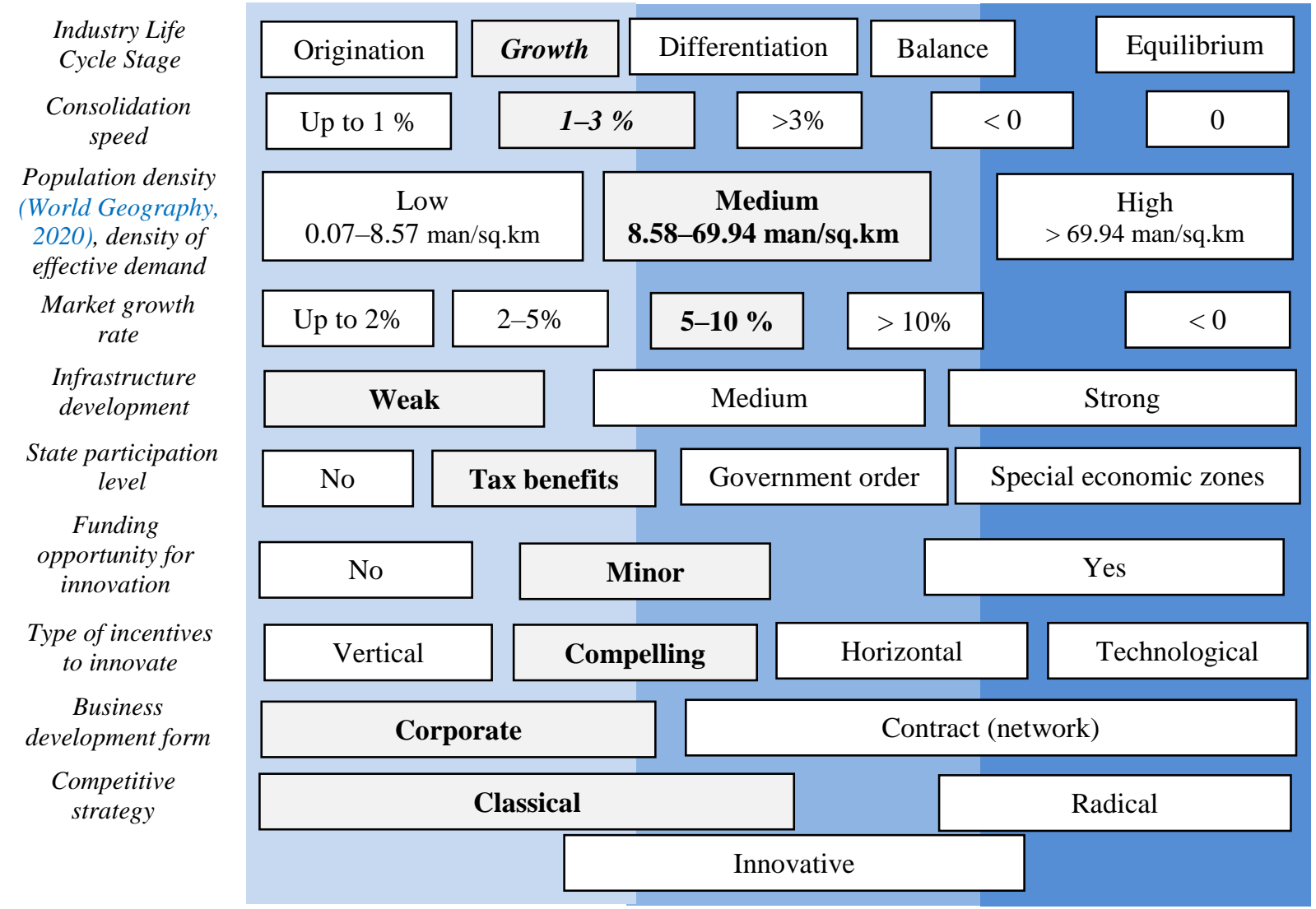

Figure 4 Decision pattern on the competitive strategy of enterprise formation

Amid high supply of energy resources in certain regions of the Russian Federation, there exist problems of low gasification and electrification. In areas with a low population 
density, it is not profitable for energy companies to invest in a centralized gas and electricity supply system (Fertikova, 2017). In case the gasification facility is located far from a large city (from $200 \mathrm{~km}$ ) and it is not included in the gas supply program, the gas mains become unavailable. The search for alternative (including innovative) ways of creating and supplying energy sources is becoming a pressing problem. In countries with developed market economies, in areas where there is a shortage of energy resources, alternative energy supply technologies have been practiced and developed. Foreign experience, including state policy in this sphere, in the creation and production of energy from various types of renewable energy sources enables domestic companies to realize their potential in those regions where the use of hydrocarbon raw materials becomes unprofitable either for the manufacturer or consumer.

Conversely, environmental safety issues are becoming more and more relevant in regions with a high quality of life and high population density, which leads to the necessity of implementation of various kinds of innovative solutions in this area. For example, the use of wireless charging technology by installing special panels while equipping transport infrastructure, and partial transfer of public and personal transport to electric vehicles. The implementation of a motorway with portable charging lanes will allow energy companies to enter new markets through the implementation of related diversification and territorial expansion strategies.

\section{Conclusions}

The growth rate and rate of industry consolidation show how critical it is for an organization to pursue an innovation strategy. In conditions when the industry is developing slowly, a company can afford to choose a classic strategy that will help maintain its position on the market thanks to the gradual modernization of products and technologies without diversion of funds for expensive development. With the rapid development of the industry, the decision to carry on a classic strategy will lead to lagging behind competitors and loss of profit.

At any stage of the industry's development, radical innovative solutions that create new industries can be developed and commercially implemented. However, as empirical data shows (Deans and Zeisel, 2004), in most cases, the maturation of radical innovative solutions and their commercial success most often fall on the stage of the industry balance.

In the modern world, strategic decisions are considered and made from the point of view of efficiency, both in terms of economic and socio-ecological indicators, which among other things, are determined by regional conditions of the strategic area of company's operation. In areas with a high population density and high income level, it is obvious that the demand for innovation will be high and rapidly changing, which will push companies to activate their innovation potential. At the same time, the speed of innovative solution adoption and implementation becomes a significant factor. Thus, the effective innovation policy of an enterprise in the conditions of the Russian economy should be differentiated, considering the specifics of regional factors.

\section{Acknowledgements}

This research work was supported by the Academic Excellence Project 5-100 proposed by Peter of the Great St. Petersburg Polytechnic University. 


\section{References}

Abushova, E., Burova, E., Suloeva, S., Shcheglova, A., 2018. Complex Approach to Selecting Priority Lines of Business by an Enterprise. In: 2017 6 $^{\text {th }}$ International Conference on Reliability, Infocom Technologies and Optimization: Trends and Future Directions, Noida, India, 2017, pp. 565-569

Aleksandr, K., Svetlana, G., Irina, Z., Elena, R., 2017. The Formation of Regional Strategy of Innovation-Industrial Development. Advances in Intelligent Systems and Computing, Volume 524, pp. 115-126

Balashova, E., Gromova, E., 2018. Russian Industrial Sector in the Conditions of the Fourth Industrial Revolution, IOP Conference Series: Materials Science and Engineering, Volume 404

Berawi, M.A., 2020. Managing Nature 5.0: The Role of Digital Technologies in the Circular Economy. International Journal of Technology, Volume 11(4), pp. 652-655

Bondarenko, N.E., 2016. Interfirm Cooperation as a Factor of Innovative Development. Bulletin of the Russian Economic University named after G.V. Plekhanov, Volume 6(90), pp. 31-40

Caiazza, R., Stanton, J., 2016. The Effect of Strategic Partnership on Innovation: An Empirical Analysis. Trends in Food Science \& Technology Journal, Volume 54, pp. 208-212

D’Aveni, R., 1995. Hypercompetitive Rivalries: Competing in Highly Dynamic Environments. Free Press, New York, USA

Deans, G.K., Zeisel, S., 2004. Winning the Merger Endgame: A Playbook for Profiting from Industry Consolidation. Alpina Publisher, Moscow, Russia

Deloitte., 2020. The Future of the Global Electric Power Industry. Preparing for New Opportunities and Threats. Available Online at https://www2.deloitte.com/content/dam/Deloitte/ru/Documents/energyresources/ru_The_future_of_global_power_sector_RUS.pdf, 2015, Accessed on October 15,2020

Dvas, G.V., Dubolazova, Y.A., 2018. Risk Assessment and Risk Management of Innovative Activity of the Enterprise. In: Proceedings of the $31^{\text {st }}$ International Business Information Management Association Conference, Milan, Italy, pp. 5650-5653

Faulkner, D., Bowman, C., 1995. The Essence of Competitive Strategy. Prentice Hall, New York, USA

Fertikova, Y.V., 2017. Trends in the Development of the Gas Industry in Modern Russia. In: Topical Issues of Economics and Management: Materials of Mezhdunar. Scientific Conference RIOR, Moscow, Russia, pp. 87-89

Fomina, N.E., Alekseev, A.A., 2018. On the Question of the Relationship of Consolidation and Innovation of Industries and Markets: A Statistical Experiment. Economics and Sociology Journal, Volume 37, pp. 27-30

Foote, N., Hensley, D., Landsberg, M., Morrison, R., 2003. The Role of the Corporate Center. McKinsey Herald, 3. Available Online at http://vestnikmckinsey.ru/organizationalmodels-and-management-systems/rol-korporativnogo-centra, Accessed on October 15,2020

Gutman, S., Rytova, E., Kravchenko, V., 2018. System of Regional Indicators for Sustainable Development of the Far North Regions. In: Proceedings of the $31^{\text {st }}$ International Business Information Management Association Conference, IBIMA 2018: Innovation Management and Education Excellence through Vision 2020, Milan, Italy

Ivanov, D.S., Kuzyk, M.G., Simachev, Y.V., 2012. Stimulating the Innovation Activity of Russian Manufacturing Companies: Opportunities and Limitations. Foresight, Volume 6(2), pp. 18-42 
Markides, K.K., Geroski, P.A., 2006. The Art of Being Second. Why "Market Discoverers" do not become the Undisputed Leaders. Vershina, Moscow, Russia

Mednikov, M.D., Sokolitsyn, A.S., Ivanov, M.V., Sokolitsyna, N.A., Yuryev, V.N., 2018. Forming Optimal Industrial Enterprise Management Strategy. In: Proceedings of the 32nd International Business Information Management Association Conference, Seville, Spain, pp. 6589-6599

Nikolova, L.V., Malinin, A.M., Rodionov, D.G., Velikova, M.D., 2017b. Performance Management of Innovation Program at an Industrial Enterprise: An Optimisation Model. In: Proceedings of the 30th International Business Information Management Association Conference, Madrid, Spain, pp. 1033-1040

Nikolova, L.V., Rodionov, D.G., Litvinenko, A.N., 2017a. Sustainability of the Business in the Conditions of Globalization. In: Proceedings of the $30^{\text {th }}$ International Business Information Management Association Conference, Madrid, Spain, pp. 417-421

Porter, M.E., 2005. Competitive Strategy: A Methodology for Analyzing Industries and Competitors. Alpina Business Books, Moscow, Russia

Ragin, F.V., 2007. Management of Company Development. Strategic Management: Workbook. IMISP, Saint-Petersburg, Russia

Setyaningrum, R., Subagyo, Wijaya, A.R., 2020. A Mathematical Model of Factors Driving Product Success in an Indonesian Market using Design of Experiment. International Journal of Technology, Volume 11(2), pp. 322-332

Shabunina, T.V., Shchelkina, S.P., Rodionov, D.G., 2017. An Innovative Approach to the Transformation of Eco-economic Space of a Region based on the Green Economy Principles. Academy of Strategic Management Journal, Volume 16(1), pp. 176-185

Sokolitsyn, A.S., Ivanov, M.V., Sokolitsyna, N.A., 2017. Statistic Modeling Industrial Enterprises Production Process Parameters. In: Proceedings of the $30^{\text {th }}$ International Business Information Management Association Conference, Madrid, Spain, pp. 10411052

Suryanegara, M., 2016. 5G as Disruptive Innovation: Standard and Regulatory Challenges at a Country Level. International Journal of Technology, Volume 7(4), pp. 635-642

World Geography. The Density of the Population of the Regions of Russia. World GEO Geography. Available Online at http://worldgeo.ru/russia/lists/?id=26\&page=1, 2020, Accessed on October 15, 2020

Zhogova, E.V., Zaborovskaia, O.V., Mokeeva, T.V., 2017. Agglomeration and Network Effects in the Spatial Development of Production. In: Proceedings of the 30th International Business Information Management Association Conference, Madrid, Spain, pp. 15221528 